\title{
Opportunities of UAVs in Orchard Management
}

\author{
Chenglong Zhang ${ }^{1,2}$, João Valente ${ }^{1}$, Lammert Kooistra ${ }^{1, *}$, Leifeng Guo ${ }^{2}$, Wensheng Wang ${ }^{3}$ \\ ${ }^{1}$ Laboratory of Geo-Information Science and Remote Sensing, Wageningen University, P.O Box 47, 6700 AA Wageningen, the \\ Netherlands - (chenglong.zhang; joao.valente; lammert.kooistra)@wur.nl \\ ${ }^{2}$ Agriculture Information Institute, Chinese Academy of Agriculture Science, Beijing China 100086 - guoleifeng@caas.cn \\ ${ }^{3}$ Key Laboratory of Agricultural Big Data, Ministry of Agriculture and Rural Affairs, Beijing China 100086 - \\ wangwensheng@caas.cn
}

KEY WORDS: UAVs, Orchard, Orchard Management, Remote Sensing

\begin{abstract}
:
The growth process of fruit trees is accompanied by a large number of monitoring and management activities, such as pruning, irrigation, fertilization, spraying, and harvesting, which are labour intensive and time consuming. In the context of precision agriculture, automation and precision orchard management not only saves labour resources and increases the income of growers, but also has great significance in improving resource utilization. Recent technological developments enable Unmanned Aerial Vehicles (UAVs, also commonly referred to as Unmanned Aerial Systems, or 'drones') to become an efficient monitoring tool for improving orchard management, that can provide growers much more detailed and precise information about fruit crops health status, geometric variables, physiological variables etc. This paper reviews the use of UAVs in orchard management, with a focus on recent UAV applications, synthetically describing the existing situation (e.g., general data processing approaches, sensing platform and sensor uploaded). The challenges and prospects of UAVs opportunities in orchard management are also summarized.
\end{abstract}

\section{INTRODUCTION}

For agriculture worldwide, feeding the growing population, reducing the rural poverty, and managing the natural resource has become the three major challenges (Mesas-Carrascosa et al., 2018). Meanwhile, every aspect of the fruit production management process is closely linked to these challenges. Increasing fruit production is an efficient way to meet the scare demands taking orchard monitoring activities such as growth, nutrient status assessment (Johansen et al., 2018). Automation and precise orchard management not only brings more profits to growers, but also reduces the damage to the environment. Thus, various investigations associated to the fruit growth circle have been taken, such as yield prediction, harvesting time judgement, early warning of disease attacks, pruning assessment and irrigation management. In the context of precision agriculture, orchard management requires real-time monitoring of yield, health status and water stress precisely. However, these types of datasets are often difficult to obtain and mostly the acquisition cost is high.

Earlier, growers have been making decisions for orchard management issues mainly based on visual inspection of color, shape, size and other information of fruits or fruit trees according to their own experience (Srivastava et al. 2017), which has professional experience requirements for observers, and often the observation results are inaccurate. Recently, more and more researcher have combined imaging technology with multiple monitoring platforms and applied them to orchard management, against empirical baseline monitoring. Varying the scale or the data collection mode of different monitoring platforms, the monitoring platforms includes manual observation (MO), handheld detection (HD), sensor network (SN), ground vehicle $(\mathrm{GV})$, unmanned aerial vehicles (UAVs), aerial sensing (AS, included airdrone and plane), spectral satellite sensing (SSS) (Figure 1). For different application scenarios, each monitoring method has its own advantages and applicability when the size and layout of the orchards are different(Shakoor et al. 2017) (Table 1). Ground-based platforms can monitor individual plants or 2 to 3 fruit trees in real time(Escola et al. 2017). Due to the small measurement distance, the obtained data is highly accurate (such as a large number of high-resolution images). Compared with ground-based platform, remote sensing is unique in terms of monitoring range and data acquisition efficiency. (Panda et al. 2010) state that variable technology such as satellite imagery, still have great potential to prove successful for orchard management. Nevertheless, SSS also shows limitation for some characterization of the orchard management, like the water properties in open canopies, due to the lack of spatial resolution (Berni et al. 2009). With the emergence of a variety of sensor miniaturization, the increasing availability of UAVs provides a quite different market for quick and precise data acquirement integrating multiple module.

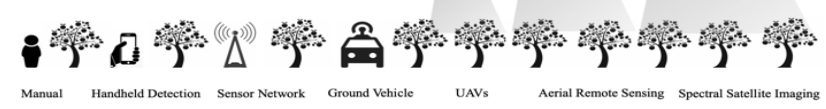

Figure 1- Multi Monitoring Platforms

* Corresponding author 


\begin{tabular}{|c|c|c|c|c|c|c|c|}
\hline Attributes & $\mathrm{MO}$ & $\mathrm{HD}$ & SN & GV & UAVs & $\mathrm{AS}$ & SSS \\
\hline Scale & $\begin{array}{l}\text { Individual } \\
\text { /plot }\end{array}$ & Individual & $\begin{array}{l}\text { Individual } \\
\text { /plot }\end{array}$ & $\begin{array}{l}\text { Individual } \\
\text { /plot }\end{array}$ & Plot/field & Plot/field & Plot/field \\
\hline $\begin{array}{l}\text { Sensor Payload } \\
\text { Size }\end{array}$ & - & miniature & $\begin{array}{l}\text { Small/ } \\
\text { Medium }\end{array}$ & $\begin{array}{l}\text { Medium/ } \\
\text { large }\end{array}$ & Small & large & Large \\
\hline Autonomous? & - & No & Yes & No & No & No & Yes \\
\hline $\begin{array}{l}\text { Data Post- } \\
\text { Processing } \\
\text { level }\end{array}$ & - & Light & Moderate & Moderate & Moderate & Moderate & $\begin{array}{l}\text { Significan } \\
\mathrm{t}\end{array}$ \\
\hline $\begin{array}{l}\text { Platform } \\
\text { Accessibility }\end{array}$ & High & Moderate & Moderate & Moderate & High & Moderate & $\begin{array}{l}\text { Low/ } \\
\text { Moderate }\end{array}$ \\
\hline
\end{tabular}

Table 1. Monitoring platforms and their attributes.

The monitoring platforms includes manual observation (MO), handheld detection (HD), sensor network (SN), ground vehicle (GV), unmanned aerial vehicles (UAVs), aerial sensing (AS, included airdrone and plane), spectral satellite sensing (SSS).

The objective of this research is to review current literature to make an inventory of the use of UAVs during the different phases of orchard management: identifying current practices and methodological issues still to be developed.

\section{MATERIALS AND METHODS}

In total 35 papers from the Web of Science database (keywords: UAV and orchard management) were found and evaluated for this review, either published or available online before 2nd April 2019. For every paper, specifications of the study (e.g., application objectives, general data processing approaches, investigation regions, type of fruit, type of UAV) were derived from the paper. The UAVs applications and main investigation objectives fell into five broad groups (several papers cover more than one of these):

1. Resource efficiency evaluation: To enhance the economical and environmental benefits, the inputs, e.g. water, pesticides, chemicals and fertilizers, should be used based on the individual fruit tree requirement evaluating the condition of each tree.

2. Biophysical and geometrical parameters measurement: To monitor the growth of fruit crops, estimate leaf area index (LAI), tree height, canopy volume and delineate fruit crops trees.

3. Applications in fruit harvest: To detect factors influencing fruit crops yield, like ethylene concentration, photosynthetically active radiation, the number of fruits on tree.

4. Health and notrient status monitoring: To monitor essential elements for fruit crops growth, like nitrogen.

5. Diseases detection: To detect and diagnosis fruit disease at earlier stage to avoid economic losses.

For every application, main system developments and methods have been described and relevant examples are provided.

\section{RESULTS}

Overall, diverse investigations from different countries have been identified mainly due to specialty fruit crop industry which is thriving in local regions (Figure 2).

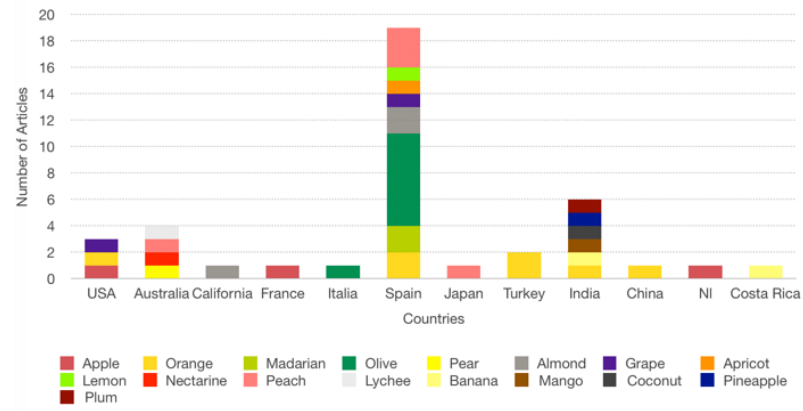

Figure 2 - Distribution of research locations and investigated fruits

\subsection{Resource efficiency evaluation}

Fruit crops are often exposed to water stress when water evaporates more than the amount stored in the soil, which leads to stomata closing and crops growth diminishing (Zhao et al. 2017). Stomatal conductance is an indicator of water stress. Based on this, the correlation between UAV imagery data of which fruit crop, such as normalized difference vegetation index (NDVI), green normalized difference vegetation index (GNDVI), and canopy temperature, and the response variables, such as stomatal conductance and yield, was demonstrated (for correlation with yield, $\mathrm{r}=0.68,0.73$, and -0.83 , respectively, and with leaf stomatal conductance, $\mathrm{r}=0.56,0.65$, and -0.63 , respectively). The imagery include multispectral and thermal infrared images while stomatal conductance measured from a leaf porometer (Espinoza et al. 2017). Water status in the soil-plantatmospheric continuum can be indicated by Stem Water Potential (SWP) which is labour intensive and time consuming to measure. With the help of UAVs, canopy NDVI showed good correlation with SWP without average pixels calculation in an orchard level. In addition, the prediction result also provides a potential for water stress quantification (Zhao et al. 2017). Compared with vegetation indices, e.g. Green Ratio (GR), Intensity (I), Normalized Difference Green Near Infrared Index (NDGNI), Saturation (S), Enhanced Normalized Difference Vegetation Index (ENDVI) showed a better performance to evaluate orchard variation in water input (Bulanon et al. 2016). Based on previous investigation, a comparison between photochemical reflectance index $\left(\mathrm{PRI}_{570}\right)$ and a chlorophyII ratio against Renormalized Difference Vegetation Index (RDVI), NDVI and Modified Triangular Vegetation Index (MTVI) was studied (Stagakis et al. 2012). Plus, NDVI calculated from UAV-based images was found to be linearly correlated with leaf cholorophyII and LAI has been measured on the same data while canopy volume, height and diameter derived from UAV-based DSM was also correlated with the ones measured in the field. Additionally, relationship between the increased canopy volume value calculated from the 
aerial data and the daily water stress integral was demonstrated (Caruso et al. 2019).

Another indicator is the Crop Water Stress Index (CWSI), which has been applied in several fruit crops. This concept could be understood by canopy $(\mathrm{Tc})$ and air temperature $(\mathrm{Ta})$ normalized difference index, basing on the fact of canopy temperature closely relates to transpiration (Gonzalez-Dugo et al. 2014). The slope of CWSI, derived from UAVs images, with time provides a novel method for water status tracking. From the investigation result, CWSI thresholds were also determined, which could help growers to make a precision irrigation management (GonzalezDugo et al. 2013). Further, a CWSI map derived from UAVs thermal images opens the possibility to assess spatial variability of water stress in orchard via using CWSI as a valuable index (Gonzalez-Dugo et al. 2014). Diverse cultivars or training systems in orchard impacts the thermal responses collected from UAVs images. To reduce this negative error, an adaptive CWSI performs a better correlation with both SWP and stomatal conductance, which contributes the application in the orchard with multi training sub-systems(Park et al. 2017). Two models, one is for canopy conductance (CC) calculation while the other is for CWSI, demonstrated the spatial analysis of water in olive orchards basing on the dataset from an airborne campaign and a UAV (Berni et al. 2009). ChIorophyII fluorescence derived from UAVs for water stress status assessment was produced, with determination coefficients of 0.57 and 0.54 for olive and peach, respectively (Zarco-Tejada et al. 2009). Besides, thermal, narrow-band indices and fluorescence retrievals derived from airborne data were also considered to be an good indicator (Zarco-Tejada et al. 2012).

For all of these investigations, thermal camera is the main information collector. However, temperature drift error is often accompanied by data acquisition using system with no temperature control unit, specifically for UAVs data acquisition system. Before image-based assessment, high resolution orthomosaics provides more accurate multispectral comparisons employing radiometric calibration based on ground system. By demonstrating it, spatial resolution obtained is even enough to assess the water status of each individual fruit crop (GomezCandon et al. 2016). According to existing investigations above, applying different vegetation indices for real-time water status estimation or mapping spatial variability of water using sensing images derived from diverse sensors mounted on UAVs has been demonstrated (Table 2). Concurrently, multi UAV platforms were used for these applications, that poses a novel way for orchard management, specifically enhancing orchard irrigation effectiveness (Table 3).

\begin{tabular}{lll}
\hline Index & Camera payload & Ref. \\
\hline NDVI & $\begin{array}{l}\text { thermal infrared; } \\
\text { multispectral }\end{array}$ & $\begin{array}{l}\text { Espinoza et al. } \\
\text { 2017; Stagakis et } \\
\text { al. 2012; Caruso } \\
\text { et al. 2019; } \\
\text { Zarco-Tejada et } \\
\text { al. 2012; Caruso } \\
\text { et al. 2019 } \\
\end{array}$ Stagakis et al. \\
& & 2012 \\
& & Stagakis et al. \\
& multispectral & Espinoza et al. \\
RDVI & multispectral & 2017; \\
MTVI & Bulanon et al. \\
& thermal infrared; & 2016; \\
GNDVI & Multispectral & Zhao et al. 2017 \\
\hline
\end{tabular}

\begin{tabular}{|c|c|c|}
\hline NDGNI & $\begin{array}{l}\text { Multispectral; } \\
\text { Video }\end{array}$ & $\begin{array}{l}\text { Bulanon et al. } \\
\text { 2016; }\end{array}$ \\
\hline SWP & thermal infrared & Park et al. 2017; \\
\hline CWSI & $\begin{array}{l}\text { Thermal; thermal } \\
\text { infrared; } \\
\text { multispectral }\end{array}$ & $\begin{array}{l}\text { Gonzalez-Dugo et } \\
\text { al. 2014; } \\
\text { Gonzalez-Dugo et } \\
\text { al. 2013; Park et } \\
\text { al. } 2017 \text {; Berni et } \\
\text { al. } 2009\end{array}$ \\
\hline GR & $\begin{array}{l}\text { Multispectral; } \\
\text { Video }\end{array}$ & $\begin{array}{l}\text { Bulanon et al. } \\
\text { 2016; }\end{array}$ \\
\hline $\mathrm{CC}$ & $\begin{array}{l}\text { thermal infrared; } \\
\text { multispectral }\end{array}$ & Berni et al. 2009 \\
\hline $\mathrm{S}$ & $\begin{array}{l}\text { Multispectral; } \\
\text { Video }\end{array}$ & $\begin{array}{l}\text { Bulanon et al. } \\
\text { 2016; }\end{array}$ \\
\hline $\mathrm{T}$ & $\begin{array}{l}\text { thermal infrared; } \\
\text { multispectral }\end{array}$ & $\begin{array}{l}\text { Espinoza et al. } \\
2017 \text {; }\end{array}$ \\
\hline I & $\begin{array}{l}\text { Multispectral; } \\
\text { Video }\end{array}$ & $\begin{array}{l}\text { Bulanon et al. } \\
\text { 2016; }\end{array}$ \\
\hline
\end{tabular}

Table 2 - Vegetation Index applied for resource efficiency

Employing thermal image processing, such as object-based method, and statistical analysis, applicability and limitation of applying CWSI to indicate water deficits in orchards was demonstrated (Gonzalez-Dugo et al. 2014). After that, three vegetation indices (NDVI,GNDVI, and canopy temperature) show a potential to estimate water status in orchard employing image processing and statistical analysis (Espinoza et al. 2017). In the process of image processing, changing the red band to blue band for NDVI calculation provided a good correlation result, combined with tuning NDVI threshold (Zhao et al. 2017). Besides, RGB image processing results could be an image mask to access the orchard variation combining the statistical analysis of spectral images (Bulanon et al. 2016). Meanwhile, taking more attention to the radiometric calibration when the image is preprocessed leads to assessment at individual fruit tree level (Gomez-Candon et al. 2016). Prior to Gaussian mixture modelling, edge extraction method, combined Sobel and Canny, and filtering can lead to pure canopy extraction accuracy enhancing combining statistical analysis. To reduce the influence of diverse training systems to thermal responses, adaptive thresholds of the parameters for CWSI calculation show unique performance using statistical analysis (Park et al. 2017). Based on specific assumptions, the canopy conductance calculation model and CWSI model were built. For the first model, simulating radiation and aerodynamic resistance meets the requirement of canopy conductance modelling (Berni et al. 2009).

\begin{tabular}{|c|c|c|c|}
\hline Index & UAVs & $\begin{array}{l}\text { Altitude } \\
(\mathrm{m})\end{array}$ & Ref. \\
\hline NDVI & $\begin{array}{l}\text { Mikrokopter } \\
\text { OktokopterXL; } \\
\text { Viewer; S1000; } \\
\text { Benzin } \\
\text { Acrobatic }\end{array}$ & $\begin{array}{l}50 / 100 \\
575 ; 70\end{array}$ & $\begin{array}{l}\text { Espinoza et al. } \\
\text { 2017; Zarco- } \\
\text { Tejada et al. } \\
\text { 2012; Caruso } \\
\text { et al. } 2019\end{array}$ \\
\hline RDVI & $\begin{array}{l}\text { Benzin } \\
\text { Acrobatic }\end{array}$ & 250 & $\begin{array}{l}\text { Stagakis et al. } \\
2012\end{array}$ \\
\hline MTVI & $\begin{array}{l}\text { Benzin } \\
\text { Acrobatic }\end{array}$ & 250 & $\begin{array}{l}\text { Stagakis et al. } \\
2012\end{array}$ \\
\hline GNDVI & $\begin{array}{l}\text { ARF } \\
\text { 6S12 }\end{array}$ & 40 & $\begin{array}{l}\text { Espinoza et al. } \\
\text { 2017; }\end{array}$ \\
\hline ENDVI & MikroKopter & & $\begin{array}{l}\text { Bulanon et al. } \\
\text { 2016; }\end{array}$ \\
\hline $\begin{array}{l}\text { Canopy } \\
\text { NDVI }\end{array}$ & mX-SIGHT & 90 & $\begin{array}{l}\text { Zhao et al. } \\
2017\end{array}$ \\
\hline NDGNI & Viewer & 150 & Bulanon et al. \\
\hline
\end{tabular}




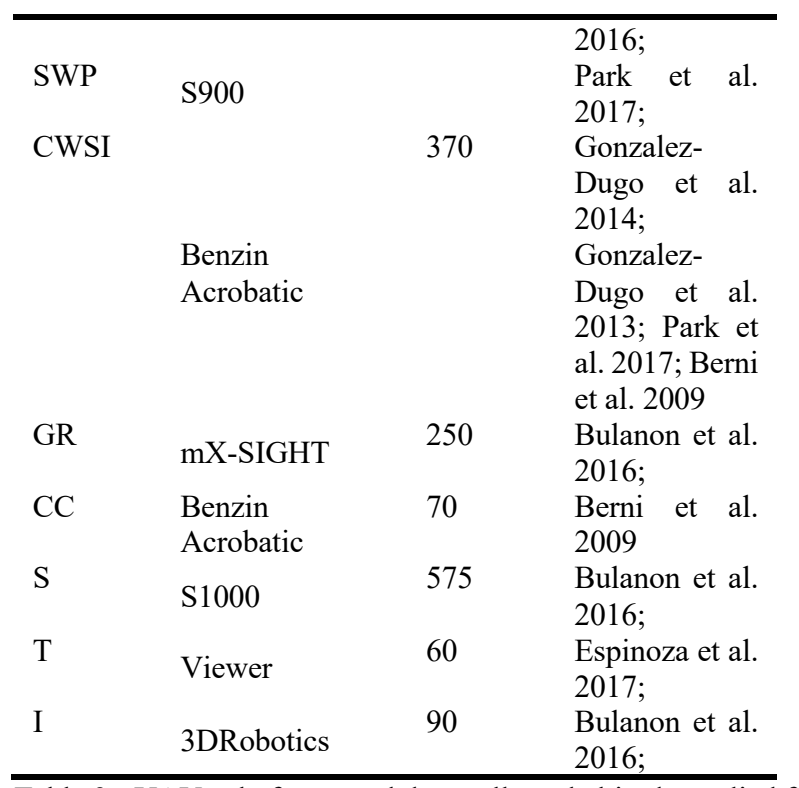

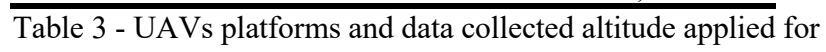
resource efficiency

\subsection{Biophysical and geometrical parameters measurement}

Pruning effects can be evaluated via extracting fruit crops structural properties such as crown perimeter, width, height and area using the multispectral images from UAVs. By doing this, significant changes in the structural properties can be observed after pruning. For data collection, variable flying height impacts fruit tree structural properties, specifically, increasing height produced decreasing crown perimeter and height measurement while less impact for crown width and Plant Projective Cover (PPC) (Johansen et al. 2018). Crown width and Crown Projection Area(CPA) measurement based on the processing of Digital Surface Model (DSM) is obtainable and reliable using a consumer-grade UAV, that also has a potential in mapping dynamical maps for orchard management. Good results were achieved and the method demonstrated it has an equivalent performance with manual delineation while field measurement could be instead by this (Mu et al. 2018). For the application of DSMs for fruit crops detection, a novel approach combined orientation symmetry information and local maxima cues with the inputs was developed. The high success investigation result was superior than the ones has been demonstrated before, with an value of $92.5 \%$ for overall $F_{1}-$ score (Ok et al. 2018b). Different fruit trees pruning strategies, i.e., the traditional, adapted and mechanical pruning treatment, provide diverse effect on tree growth. To quantify the impact of this after pruning and a year after, UAV technology and object-based image analysis (OBIA) was combined, with a result that adapted pruning benefits tree height when intensity was lower than $10 \%$. The quantified parameters were tree height, crown volume and projected canopy area (PCA) (Jimenez-Brenes et al. 2017).

A UAV-derived algorithm for mapping 3-D almond tree volume and volume growth produced an overall root mean square error of $0.39 \mathrm{~m}$, that shows the capability of UAVs for accurately mapping fruit crops geometric features. The dataset generated was collected over diverse phenological stages in two years (Torres-Sanchez, de Castro, et al. 2018). Another investigation showed a 3-D geometric features computation with good performance in canopy area, with an quantification accuracy of $97 \%$, tree heights and crown volumes estimations (TorresSanchez et al. 2015). In the process of fruit crops 3-D reconstruction in UAV photogrammetry, generating DSM takes a lot of time, that enables it a challenge in the application. Several DSMs with diverse forward laps were created to generate the optimal processing time. According to the accuracy of these models, the combination of $100 \mathrm{~m}$ flying altitude, compared with $50 \mathrm{~m}$, and a forward lap of $95 \%$ is the best, with a tree volume estimation accuracy of $95 \%$. In addition, time saving performance reached to $85 \%$, compared with the maximum overlap (Torres-Sanchez, et al. 2018b). Fruit trees 3-D reconstruction plays an critical role in remote sensing while 2-D delineation dominates the level of a 3-D reconstruction. To achieve a successful 3-D reconstruction, a novel approach for 2$\mathrm{D}$ delineation accuracy improvement was developed basing on dense photogrammetric digital surface models (DSMs). A good balance between accuracy and recall measures was shown after extensive comparisons with eight DSMs (Ok et al. 2018a).

Compared with a costly light detection and ranging (LiDAR) system, usually composes of a complex computation system, an assessment provided by inexpensive UAV sensing system with consumer-grade camera was investigated, specifically, for the fruit trees canopy biophysical parameter, like tree height quantification (Zarco-Tejada et al. 2014). Another investigation showed the potential of UAV-based tree crown delineation in small holder field using aerial dataset from RGB cameras. The experimental subjects were banana, mango and coconut (Kestur et al. 2018). In some multi-story cropping pattern, like a cultivation system mixed with banana, orange and bamboo, crops discrimination has been tested, depending on diverse spectral response and crop height. Comparison between the discrimination employed vegetation index, NDVI, Normalized Difference Red Edge Index (NDRE) and Green Normalized Difference Vegetation Index (GNDVI), and the one based on DSM and digital terrain model was also provided(Handique et al. 2017). According to existing investigations above, variable research objectives related to biophysical and geometrical parameters measurement for orchard precise management has been demonstrated (Table 4).

\begin{tabular}{lll}
\hline Objectives & Camera payload & Ref. \\
\hline Crown perimeter & multispectral & Johansen et al. \\
& & $2018 ;$ \\
Crown width & Multispectral; & Johansen et al. \\
& Digital camera & 2018; Mu et al. \\
& & $2018 ;$ \\
Tree height & Multispectral; & Johansen et al. \\
& Point-and-shoot & 2018; Jimenez- \\
& camera; color- & Brenes et al. \\
& infrared & 2017; Zarco- \\
& & Tejada et al. 2014 \\
PPC & multispectral & Johansen et al. \\
& & 2018 \\
CPA & Digital camera & Mu et al. 2018; \\
Crown volume & Point-and-shoot & Jimenez-Brenes \\
& camera; Visible- & et al. 2017; \\
& RGB & Torres-Sanchez et \\
& & al. 2018a \\
PCA & Point-and-shoot & Jimenez-Brenes \\
& camera & et al. 2017; \\
& & Gonzalez-Dugo et \\
& & al. 2013; Park et \\
& & al. 2017; Berni et \\
& & al. 2009 \\
2-D delineation & Digital camera & Ok et al. 2018a; \\
3-D & Digital camera & Kestur et al. 2018 \\
\hline
\end{tabular}

Table 4 - Variable research objectives contribution 
Methods for olive trees delineation, like Geographic ObjectBased Image Analysis (GeoOBIA), had a poor performance for lychee trees, which needs more spectral information(Johansen et al. 2018). However, more investigations applied OBIA methodology provided a good computation for 3-D tree features (Jimenez-Brenes et al. 2017). In the process of 2-D delineation, orientation-based radial symmetry has a unique performance. Afterwards, delineating trees though active contours, where the influence region was squared up, was demonstrated. Besides, a canopy erroneous detection filter with no height thresholds was also present (Ok Ozdarici-Ok, 2018a). For irregular crown shape extraction, like peach trees, a combination of adaptive thresholds and watershed segmentation was also of interest, specifically, individual fruit trees could be extracted (Mu et al. 2018). As to generating ortho-mosaics and DSMs, effects of input image pixel resolution was simulated, with a result that stable relationships lie in the pixel resolutions between 5 and $30 \mathrm{~cm}$ while unstable happen when it is lower than $35 \mathrm{~cm}$ (Zarco-Tejada et al. 2014). A point cloud derived from a UAV was the only input, based on this, an automatically executed procedure composed of digital terrain model generation, crown delineation and another two steps was applied (Torres-Sanchez et al. 2018a). In the context of tree crown delineation, methods based on extreme learning machine (ELM) was comparable to KMeans, even better. ELM is a neural network classifier, which applied as an important role in supervised classification. In the case of removing no tree pixels, cause by spectral intensities similarities, spatial classification was carried out with geometrical property filtering. In the case of segmenting connected crowns, watershed algorithm had a good performance using images marked by distance transform. The neural network classifier is a single hidden layer feed forward one(Kestur et al. 2018). Regarded DSM as the inputs, a combination of local maxima cues information and orientation symmetry performed better in the final transform(Ok OzdariciOk, 2018b). In an OBIA environment, a time-saving procedure was developed, by reducing the spectral information in the tree detection stage (Torres-Sanchez et al. 2018b).

\subsection{Applications in fruit harvest}

UAVs provide an environment that can be redeveloped, for both software and hardware. According to different research objectives, researchers can carry out various monitoring purposes by mounting different sensor acquisition devices on the drones. Optimal harvest date benefits fruit yield, by avoiding fruit spoiling. On the other hand, that also provides an efficient way to enhance resource utilization. With the development of gas detection technology, the potential of using aerial remote sensing for optimal harvest time detection was demonstrated. Uploading a small ethylene sensor to the UAV, field tests showed that the detection probability is $10 \%$ while UAV flying altitude less than 6 meters. The methodology employed here mainly is modelling and simulation (Valente et al. 2019). Optimizing the harvest process in an orchard normally depends on detailed and precise information about yield estimation, that benefits the management for labour allotment, packing etc. Usually it is not easy to count the fruits on tree, due to occlusions from neighbouring ones or foliage. However, an investigation based on computer version and deep learning provided a novel solution for the yield estimation. Dataset acquired was oranges in daylight and apples at night. The counting algorithm developed here had a nice performance with limited dataset, even could annotate the apples which is hard for human to label well. Methodology employed were convolutional network and linear regression model (Chen et al. 2017).
Radiation levels of fruit crops canopy is a critical element for the photosynthesis, specifically, that is for dry matter production and the crops growth determination. A model based on multispectral imagery derived from UAVs was demonstrated for mapping the intercepted photosynthetically active radiation (fIPAR) in peach and citrus orchards. Plots with a gradient in the structure of fruit crops canopy were selected, and leaf optical properties, sun geometry parameters used for canopy reflectance, vegetation indices, like NDVI, and fIPAR assessment were also studied for the 3-D canopy model (Guillen-Climent et al. 2012). Another photosynthesis-related index, carotenoids $\left(\mathrm{C}_{\mathrm{x}+\mathrm{c}}\right)$, estimation in a vineyard was demonstrated, with a RMSE below $1.3 \mu \mathrm{g} / \mathrm{cm}^{2}$ when the targeted vines with no shadow and background effects (Zarco-Tejada et al. 2013a).

NDVI variation map derived from UAV-based images was compared with spatial soil quality and banana production data, such as bunch weight, length of largest finger and yield. Good results showed that NDVI index was significantly correlated with bunch weight, length of largest finger, yield and banana loss, and was not correlated with the soil quality. Methods employed here were image processing and statistical analysis(Machovina et al. 2016). Canopy florescence, NDVI, EVI, chlorophyII content, light use efficiency and canopy chlorophyII were critical indicators for gross primary production monitoring in orchard. But when these indices were derived from UAVs, less monitoring function was observed, though small physiological changes was obtained (Zarco-Tejada et al. 2013b).

To estimate the fIPAR, 3-D radiative transfer model and forest light interaction model were used. A fIPAR map based on scaling-up and model inversion conducted with a look-up table or 3-D model yielded RMSE error below 0.10 or 0.09 , respectively (Guillen-Climent et al. 2012).

\subsection{Diseases detection}

Some fruit industries are suffering from serious threats to deadly diseases worldwide. Like the Verticillium Wilt (VW) in olive trees, which infected the vascular system of fruit crops, has a great impact in blocking water flow in crops. As the most limiting disease of olive trees, VW could be earlier detected, and severity levels could be discriminated as well using multispectral, hyperspectral and thermal images derived from UAVs. Diverse vegetation indices were studied, i.e., chlorophyII $a+b$, blue/green/red/B/G/R indices, NDVI and CWSI. Meanwhile, leaf and tree-crown levels investigation were also provide. Results showed that for the earlier detection, CWSI, visible ratios $\mathrm{B} / \mathrm{BG} / \mathrm{BR}$ as well as fluorescence were carried out as the indicators, while photochemical reflectance index (PRI), chlorophyll, carotenoid indices, and the $\mathrm{R} / \mathrm{G}$ ratio performed better for the severity levels assessment (Calderon et al. 2013). Huanglongbing (HLB), also known as citrus greening, greatly threatens the citrus industry worldwide. HLB is infected by a bacterium and spread by the insect vector named psyllid (Diaphorina citri). When obvious symptoms can be seen, the only treatment for the infected trees is cutting off by now, due to no treatment was found up to now. To achieve earlier detection avoiding more healthy trees to be infected, a study on this was carried out using high-resolution images from UAVs. Highresolution images from a UAV uploaded multi-bands (from 530 to $900 \mathrm{~nm}$ ) sensor and lower resolution images derived from an aircraft were compared, for the detection accuracy. Results shows that both the two sensing designs is capable of detecting HLB disease at $710 \mathrm{~nm}$ reflectance or with NIR-R index values. In addition, detection based on the dataset from UAVs has a better 
performance, with detection accuracies lie in the range of $67-85 \%$ (Garcia-Ruiz et al. 2013).

Earlier, pesticides spraying mainly relies on manual labour. UAVs with electric sprayer opens the opportunities to save labour work. More recent, an evaluation for UAV spraying and manual spraying was demonstrated. Different effects on the control against citrus leafminer (Phyllocnistis Citrella Stainton) and the differentiation of cost under diverse citrus tree shapes were studied. Good results showed that UAV spraying is more efficient, with lower cost (Zhang et al. 2017).

Statistical analysis combined with standard analysis of variance normally benefits checking out good indicators for disease detection and severity levels discrimination (Calderon et al. 2013). After seven vegetation indices were calculated, regression analysis was employed for the features extraction. For classification assessment, support vector machine(SVM) was found to be better, compared with linear SVM, linear discriminant analysis (Garcia-Ruiz et al. 2013).

\subsection{Health status}

Nitrogen is an essential factor for fruit crops growth, i.e., nitrogen had an impact on the crops vigor and yield in a pear orchard. Two reflectance measurements were demonstrated, one is canopyscale reflectance measurement with the contribution of UAVs, the other is leaf-scale measurement in laboratory level. For the canopy-scale measurement, a result for root mean square error (RMSE) value is $0.24 \% \mathrm{~N}$, resulted in a new index, modified canopy chlorophyII Content Index, which provided a support for spatial variation of leaf $\mathrm{N}$ concentration (Perry et al. 2018). In a thermal image, if different images indicate different temperature values for a same location in the terrain, thermal drift happens. Although thermal sensors attached to a UAV could produce a good assessment for water status in orchards, most of the sensors applied with no temperature control unit could not fulfil the requirements for thermal images accuracy, lower than $1 \mathrm{C}^{\circ}$. Based on redundant information obtained from multiple overlapping images, a correction methodology was developed. The novel method yielded an accuracy greater than $1 \mathrm{C}^{\circ}$, compared with existing methodology which needs additional in-flight calibration (Mesas-Carrascosa et al. 2018).

Image processing and analysis were employed for the canopy reflectance measurement, specifically, for the nitrogen status estimation in a pear orchard (Perry et al. 2018). For thermal drift correction, six mathematical correction models were build up, and a line method defines the relationship between sensor temperature and absolute temperature was applied (MesasCarrascosa et al. 2018).

\section{DISCUSSIONS}

In the articles previously introduced, most studies focus on the use of resources efficiency in orchards, such as monitoring water status to guide precision irrigation. The reasons for this are related to the close relationship between the fruit industry and water resources, and the trend of global water shortage. However, correlation between vegetation indices and other fruits also needs to be quantified (Mesas-Carrascosa et al. 2018). Secondly, more investigations are about the monitoring of biophysical information of fruit crops, which is the most basic and most important part of the precise management of orchard. On this basis, the monitoring research on the nutritional status of fruit trees is also showing an increasing trend, which is not only important for increasing the output of fruit industry, but also important for guiding the use of chemical fertilizers and pesticides. Of course, for the low cost of color camera detection, research on determining the optimal harvest time for orchard yield estimation has also increased. So far, the state of early warning monitoring research on fruit tree diseases has not shown an objective trend. Analysis of the reasons may be due to the fact that most fruit tree diseases have no fatal effects, but like HLB disease, because of its fatal impact on the related fruit industry has also attracted more researchers attention. In addition, the complexity of pathological analysis of disease detection is also an important factor restricting related research. In summary, based on the biophysical information monitoring of fruit trees, UAVs have a very promising application prospect in the orchard precise management because of their fast, efficient and low monitoring costs.

\section{OUTLOOK}

Overall the use of UAVs is largely underutilized in orchard management. Despite this, with the support of the new agricultural aviation policy, the global application of UAVs will continue to increase, and growers and fruit industry companies can benefit from the high efficiency in orchard management. Of course, the biggest beneficiary is the consumer. However, UAVs and a variety of sensors that can be equipped to UAVs manufacturers must reduce costs to benefit more people and more industries. At the same time, the detection and identification of some of the deadly diseases of fruit trees and the challenges of UAV-based precision spray systems cannot be ignored. Although agricultural drones have been successfully used in some countries, the application cost is still an important obstacle to the widespread application of UAVs in the precision management of orchards. In addition, the accuracy of UAVs in detection and monitoring applications is severely affected by uncertainties and variable conditions in the environment and is a limiting condition for their application.

The application scenarios for future UAVs will be a combination of aerial remote sensing, real-time image processing and variable-rate aerospace applications. The monitoring system carried by UAVs processes the aerial image in real time to retrieve and diagnose fruit trees, soil, environmental information, and then respond accordingly to various automated systems, such as using variable rate spraying for individual fruit trees. In the context of multidisciplinary cross-applications, computer graphics technology will be able to provide a digital map of individual fruit trees in an orchard using automatic navigation, which is not out of reach. In addition, orchard application services provided by local governments, agricultural cooperatives and professional companies may be a trend.

\section{ACKNOWLEDGEMENTS}

This research was supported by Fundamental Research Funds of AII-CAAS (JBYW-AII-2019-19) and by the SPECTORS proj ect (143081), which is funded by the European cooperation prog ram INTERREGDeutschland-Nederland

\section{REFERENCES}

Berni, J. A. J., Zarco-Tejada, P. J., Sepulcre-Canto, G., Fereres, E., Villalobos, F., 2009. Mapping canopy conductance and CWSI 
in olive orchards using high resolution thermal remote sensing imagery. Remote Sensing of Environment, 113(11), 2380-2388.

Bulanon, D. M., Lonai, J., Skovgard, H., Fallahi, E., 2016. Evaluation of Different Irrigation Methods for an Apple Orchard Using an Aerial Imaging System. Isprs International Journal of Geo-Information, 5(6). doi.org/10.3390/ijgi5060079.

Calderon, R., Navas-Cortes, J. A., Lucena, C., Zarco-Tejada, P. J., 2013. High-resolution airborne hyperspectral and thermal imagery for early, detection of Verticillium wilt of olive using fluorescence, temperature and narrow-band spectral indices. Remote Sensing of Environment, 139, 231-245.

Caruso, G., Zarco-Tejada, P. J., Gonzalez-Dugo, V., Moriondo, M., Tozzini, L., Palai, G., et al.Gucci, R., 2019. High-resolution imagery acquired from an unmanned platform to estimate bioph ysical and geometrical parameters of olive trees under different $i$ rrigation regimes. Plos One, 14(1). doi.org/10.1371/journal.pon e.0210804.

Chen, S. W., Shivakumar, S. S., Dcunha, S., Das, J., Okon, E., Qu, C., et al.Kumar, V., 2017. Counting Apples and Oranges With Deep Learning: A Data-Driven Approach. IEEE Robotics and Automation Letters, 2(2), 781-788.

Escola, A., Martinez-Casasnovas, J. A., Rufat, J., Arno, J., Arbones, A., Sebe, F., et al.Rosell-Polo, J. R., 2017. Mobile terrestrial laser scanner applications in precision fruticulture/horticulture and tools to extract information from canopy point clouds. Precision Agriculture, 18(1), 111-132.

Espinoza, C. Z., Khot, L. R., Sankaran, S., Jacoby, P. W., 2017. High Resolution Multispectral and Thermal Remote SensingBased Water Stress Assessment in Subsurface Irrigated Grapevines. Remote Sensing, 9(9). doi.org/10.3390/rs9090961.

Garcia-Ruiz, F., Sankaran, S., Maja, J. M., Lee, W. S., Rasmussen, J., Ehsani, R., 2013. Comparison of two aerial imaging platforms for identification of Huanglongbing-infected citrus trees. Computers and Electronics in Agriculture, 91, 106115 .

Gomez-Candon, D., Virlet, N., Labbe, S., Jolivot, A., Regnard, J. L., 2016. Field phenotyping of water stress at tree scale by UAVsensed imagery: new insights for thermal acquisition and calibration. Precision Agriculture, 17(6), 786-800.

Gonzalez-Dugo, V., Zarco-Tejada, P., Nicolas, E., Nortes, P. A., Alarcon, J. J., Intrigliolo, D. S., Fereres, E., 2013. Using high resolution UAV thermal imagery to assess the variability in the water status of five fruit tree species within a commercial orchard. Precision Agriculture, 14(6), 660-678.

Gonzalez-Dugo, V., Zarco-Tejada, P. J., Fereres, E., 2014. Applicability and limitations of using the crop water stress index as an indicator of water deficits in citrus orchards. Agricultural and Forest Meteorology, 198, 94-104.

Guillen-Climent, M. L., Zarco-Tejada, P. J., Berni, J. A. J., North, P. R. J., Villalobos, F. J., 2012. Mapping radiation interception in row-structured orchards using 3D simulation and high-resolution airborne imagery acquired from a UAV. Precision Agriculture, $13(4), 473-500$
Handique, B. K., Khan, A. Q., Goswami, C., Prashnani, M., Gupta, C., Raju, P. L. N., 2017. Crop Discrimination Using Multispectral Sensor Onboard Unmanned Aerial Vehicle. Proceedings of the National Academy of Sciences India Section a-Physical Sciences, 87(4), 713-719.

Jimenez-Brenes, F. M., Lopez-Granados, F., de Castro, A. I., Torres-Sanchez, J., Serrano, N., Pena, J. M., 2017. Quantifying pruning impacts on olive tree architecture and annual canopy growth by using UAV-based 3D modelling. Plant Methods, 13. doi.org/10.1186/s13007-017-0205-3.

Johansen, K., Raharjo, T., McCabe, M. F., 2018. Using MultiSpectral UAV Imagery to Extract Tree Crop Structural Properties and Assess Pruning Effects. Remote Sensing, 10(6). doi.org/10.3390/rs10060854.

Kestur, R., Angural, A., Bashir, B., Omkar, S. N., Anand, G., Meenavathi, M. B., 2018. Tree Crown Detection, Delineation and Counting in UAV Remote Sensed Images: A Neural Network Based Spectral-Spatial Method. Journal of the Indian Society of Remote Sensing, 46(6), 991-1004.

Machovina, B. L., Feeley, K. J., Machovina, B. J., 2016. UAV remote sensing of spatial variation in banana production. Crop \& Pasture Science, 67(12), 1281-1287.

Mesas-Carrascosa, F. J., Perez-Porras, F., de Larriva, J. E. M., Frau, C. M., Aguera-Vega, F., Carvajal-Ramirez, F., et al.GarciaFerrer, A., 2018. Drift Correction of Lightweight Microbolometer Thermal Sensors On-Board Unmanned Aerial Vehicles. Remote Sensing, 10(4). doi.org/10.3390/rs10040615.

Mu, Y., Fujii, Y., Takata, D., Zheng, B. Y., Noshita, K., Honda, K., et al.Guo, W., 2018. Characterization of peach tree crown by using high-resolution images from an unmanned aerial vehicle. Horticulture Research, 5. doi.org/10.1038/s41438-018-0097-z.

Ok, A. O., Ozdarici-Ok, A., 2018a. 2-D delineation of individual citrus trees from UAV-based dense photogrammetric surface models. International Journal of Digital Earth, 11(6), 583-608.

Ok, A. O., Ozdarici-Ok, A., 2018b. Combining Orientation Symmetry and LM Cues for the Detection of Citrus Trees in Orchards From a Digital Surface Model. Ieee Geoscience and Remote Sensing Letters, 15(12), 1817-1821.

Panda, S. S., Hoogenboom, G., Paz, J. O., 2010. Remote Sensing and Geospatial Technological Applications for Site-specific Management of Fruit and Nut Crops: A Review. Remote Sensing, 2(8), 1973-1997.

Park, S., Ryu, D., Fuentes, S., Chung, H., Hernyndez-Montes, E., O'Connell, M., 2017. Adaptive Estimation of Crop Water Stress in Nectarine and Peach Orchards Using High-Resolution Imagery from an Unmanned Aerial Vehicle (UAV). Remote Sensing, 9(8). doi.org/10.3390/rs9080828.

Perry, E. M., Goodwin, I., Cornwall, D., 2018. Remote Sensing Using Canopy and Leaf Reflectance for Estimating Nitrogen Status in Red-blush Pears. Hortscience, 53(1), 78-83.

Shakoor, N., Lee, S., Mockler, T. C., 2017. High throughput phenotyping to accelerate crop breeding and monitoring of diseases in the field. Curr Opin Plant Biol, 38, 184-192. 
Srivastava, S., Sadistap, S., 2017. Non-destructive sensing methods for quality assessment of on-tree fruits: a review. Journal of Food Measurement and Characterization, 12(1), 497526.

Stagakis, S., Gonzalez-Dugo, V., Cid, P., Guillen-Climent, M. L., Zarco-Tejada, P. J., 2012. Monitoring water stress and fruit quality in an orange orchard under regulated deficit irrigation using narrow-band structural and physiological remote sensing indices. Isprs Journal of Photogrammetry and Remote Sensing, $71,47-61$.

Torres-Sanchez, J., de Castro, A. I., Pena, J. M., Jimenez-Brenes, F. M., Arquero, O., Lovera, M., Lopez-Granados, F., 2018a. Mapping the 3D structure of almond trees using UAV acquired photogrammetric point clouds and object-based image analysis. Biosystems Engineering, 176, 172-184.

Torres-Sanchez, J., Lopez-Granados, F., Borra-Serrano, I., Pena, J. M., 2018b. Assessing UAV-collected image overlap influence on computation time and digital surface model accuracy in olive orchards. Precision Agriculture, 19(1), 115-133.

Torres-Sanchez, J., Lopez-Granados, F., Serrano, N., Arquero, O., Pena, J. M., 2015. High-Throughput 3-D Monitoring of Agri cultural-Tree Plantations with Unmanned Aerial Vehicle (UAV) Technology. Plos One, 10(6). doi.org/10.1371/journal.pone.013 0479 .

Valente, J., Almeida, R., Kooistra, L., 2019. A Comprehensive Study of the Potential Application of Flying Ethylene-Sensitive Sensors for Ripeness Detection in Apple Orchards. Sensors (Basel), 19(2). doi.org/10.3390/s19020372.

Zarco-Tejada, P. J., Berni, J. A. J., Suárez, L., Sepulcre-Cantó, G., Morales, F., Miller, J. R., 2009. Imaging chlorophyll fluorescence with an airborne narrow-band multispectral camera for vegetation stress detection. Remote Sensing of Environment, 113(6), 1262-1275.

Zarco-Tejada, P. J., Diaz-Varela, R., Angileri, V., Loudjani, P., 2014. Tree height quantification using very high resolution imagery acquired from an unmanned aerial vehicle (UAV) and automatic 3D photo-reconstruction methods. European Journal of Agronomy, 55, 89-99.

Zarco-Tejada, P. J., Gonzalez-Dugo, V., Berni, J. A. J., 2012. Fluorescence, temperature and narrow-band indices acquired from a UAV platform for water stress detection using a microhyperspectral imager and a thermal camera. Remote Sensing of Environment, 117, 322-337.

Zarco-Tejada, P. J., Guillén-Climent, M. L., HernándezClemente, R., Catalina, A., González, M. R., Martín, P., 2013a. Estimating leaf carotenoid content in vineyards using high resolution hyperspectral imagery acquired from an unmanned aerial vehicle (UAV). Agricultural and Forest Meteorology, 171$172,281-294$.

Zarco-Tejada, P. J., Morales, A., Testi, L., Villalobos, F. J., 2013b. Spatio-temporal patterns of chlorophyll fluorescence and physiological and structural indices acquired from hyperspectral imagery as compared with carbon fluxes measured with eddy covariance. Remote Sensing of Environment, 133, 102-115.
Zhang, P., Wang, K. J., Lyu, Q., He, S. L., Yi, S. L., Xie, R. J., et al.Deng, L., 2017. DROPLET DISTRIBUTION AND CONTROL AGAINST CITRUS LEAFMINER WITH UAV SPRAYING. International Journal of Robotics \& Automation, 32(3), 299-307.

Zhao, T. B., Stark, B., Chen, Y. Q., Ray, A. L., Doll, D., 2017. Challenges in Water Stress Quantification Using Small Unmanned Aerial System (sUAS): Lessons from a Growing Season of Almond. Journal of Intelligent \& Robotic Systems, $88(2-4), 721-735$. 